\title{
Longitudinal Epigastric Incision for Caesarean Section in a Morbidly Obese Patient in a Low-Resource Setting (Cameroon): A Case Report
}

\author{
Florent Ymele Fouelifack ${ }^{1,2,3}\left(\mathbb{D}\right.$, Wilfried Loic Tatsipie ${ }^{4}$, Armand Kamga Talom ${ }^{*}{ }^{*}$, \\ Anyimbi Ofeh Mosman' ${ }^{(\mathbb{D})}$, Hortence Fouedjio ${ }^{2,4}$ \\ ${ }^{1}$ Department of Surgery and Specialties, Higher Institute of Medical Technology of Nkolondom, Yaounde, Cameroon \\ ${ }^{2}$ Obstetrics and Gynecology Unit, Yaounde Central Hospital, Yaounde, Cameroon \\ ${ }^{3}$ Research, Education and Health Associative Group GARES-Falaise, Dschang, Cameroon \\ ${ }^{4}$ Department of Gynecology and Obstetrics, Faculty of Medicine and Biomedical Sciences, University of Yaounde I, \\ Yaounde, Cameroon \\ Email: yfouelifack@gmail.com, tatsipien@yahoo.fr, *kamtatar@gmail.com, mosmanofeh@yahoo.com, fouedjiojeanne@yahoo.fr
}

How to cite this paper: Fouelifack, F.Y., Tatsipie, W.L., Talom, A.K., Mosman, A.O. and Fouedjio, H. (2021) Longitudinal Epigastric Incision for Caesarean Section in a Morbidly Obese Patient in a Low-Resource Setting (Cameroon): A Case Report. Open Journal of Obstetrics and Gynecology, 11, 929-934.

https://doi.org/10.4236/ojog.2021.118088

Received: June 26, 2021

Accepted: July 30, 2021

Published: August 2, 2021

Copyright $\odot 2021$ by author(s) and Scientific Research Publishing Inc. This work is licensed under the Creative Commons Attribution International License (CC BY 4.0).

http://creativecommons.org/licenses/by/4.0/ (c) (i) Open Access

\begin{abstract}
Obesity is a metabolic condition associated with a significant morbidity and mortality rate. In the pregnant context, this risk is even higher because of the contingent of metabolic and haemodynamic complications present in the ante-, intra- and post-partum periods. In these people, the recommended delivery method is caesarean section, which is not easy to perform. Our aim is to explain the particularities and advantages of epigastric incision in obese women during a caesarean section. The authors report the case of a patient who was admitted to the maternity ward of the Yaounde Central Hospital for management of a post-date, and in whom an elective caesarean section was indicated with an epigastric approach. The vertical supra umbilical incision should be recommended because it is subject to fewer complications and reduces the operating time and hospital stay.
\end{abstract}

\section{Keywords}

Obesity, Caesarean Section, Epigastric Incision

\section{Introduction}

The relative frequency of obesity in the pregnant population is increasing at an alarming rate [1]. An increasing number of patients with a body mass index 
(BMI) $>50 \mathrm{~kg} / \mathrm{m}^{2}$, the so-called super obesity, are observed [2], which in our context leads to obstetric, anaesthetic and logistical challenges. We describe the management of caesarean delivery (CD) in a parturient with a BMI of $55 \mathrm{~kg} / \mathrm{m}^{2}$, with emphasis on the patient's profile, operative techniques, complications, and outcome. We are not aware of any previous reports describing caesarean section management in a parturient with a BMI $>50 \mathrm{~kg} / \mathrm{m}^{2}$ in the African setting.

\section{Patient and Observation}

We report a case of Caesarean section with an epigastric approach in a 32-year-old pregnant woman, married, gravida 3 with a history of two normal term deliveries by vaginal route and whose last living child was 7 years old. She had been seen in the department for an overdue delivery at 41 weeks (W) and +2 days (D). It is important to note that, there were no pregnancy complications in this patient. The history of the current pregnancy revealed an unremarkable prenatal follow-up, and an ultrasound performed in the $3^{\text {rd }}$ trimester showed an evolving monofoetal intrauterine pregnancy of $40 \mathrm{~W}$ with an estimated fetal weight of 3744 grams. The initial clinical examination of the patient revealed a good general condition, morbid obesity with a BMI of $55.1 \mathrm{~kg} / \mathrm{m}^{2}$, and other vital parameters were normal. The general examination was unremarkable. The obstetrical examination revealed active fetal movements, a uterine height of $50 \mathrm{~cm}$ with a large fatty panicle, the presentation was poorly appreciated as well as the fetal heart sounds on Doppler. The gynecological examination showed a long, posterior, soft cervix, $2 \mathrm{~cm}$ dilated, cephalic presentation and intact membranes. We made the diagnosis of an evolving intrauterine pregnancy of $41 \mathrm{~W}+2 \mathrm{D}$ on morbid obesity and an elective caesarean section was indicated. The preoperative check-up was normal, and the preanaesthetic consultation was done. The caesarean section was performed at 42 weeks under general anaesthesia with orotracheal intubation. The patient was placed in the supine position with her hands crossed, after asepsis and sterile draping, the incision was median above the umbilicus (Figure 1). The tissues were dissected plane by plane. The aponeurosis was incised vertically as well as the peritoneum. The hysterotomy was median, corporal anterior (Figure 2), through the placenta and a cephalic fetal extraction was done. The extracted neonate was female with an APGAR score of 8/10 and a birth weight of 4045 grams. Delivery was done manually, hysterorrhaphy was done in 2 planes (Figure 3), parietal closure was done plane by plane, with the skin closed in Blair-Donatti stitches (Figure 4). The patient was admitted to the surgical intensive care unit for postoperative follow-up and then transferred to the post-natal where she was discharged on day seven postoperation with a favourable evolution and satisfactory healing of the surgical wound.

\section{Discussion}

Obesity in pregnancy is a real concern for the African obstetricians, both because of the westernisation of dietary habits and because of the marterno-foetal 


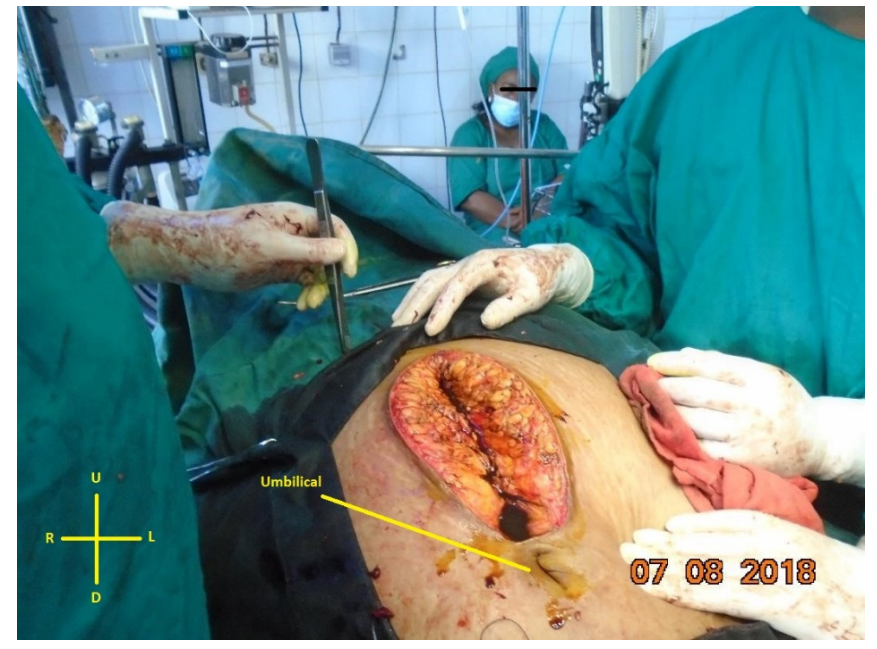

Figure 1. Median supra-umbilical skin incision. Title: $\mathbf{U}=\mathrm{Up}, \mathbf{D}=$ Down, $\mathbf{R}=$ Right, $\mathbf{L}=$ Left.

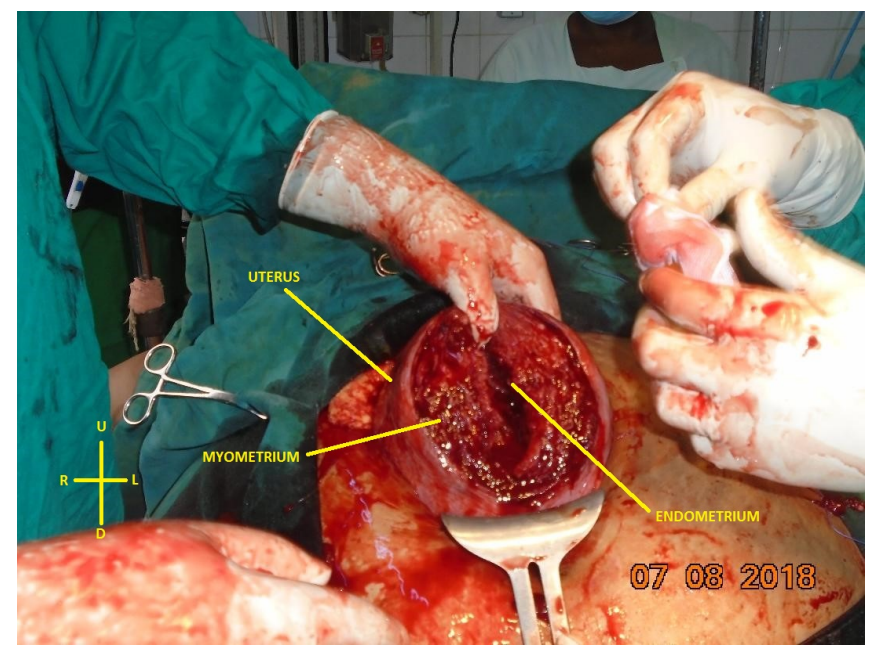

Figure 2. Externalisation of the uterus after fetal extraction. Title: $\mathbf{U}=\mathrm{Up}, \mathbf{D}=$ Down, $\mathbf{R}$ $=$ Right, $\mathrm{L}=$ Left.

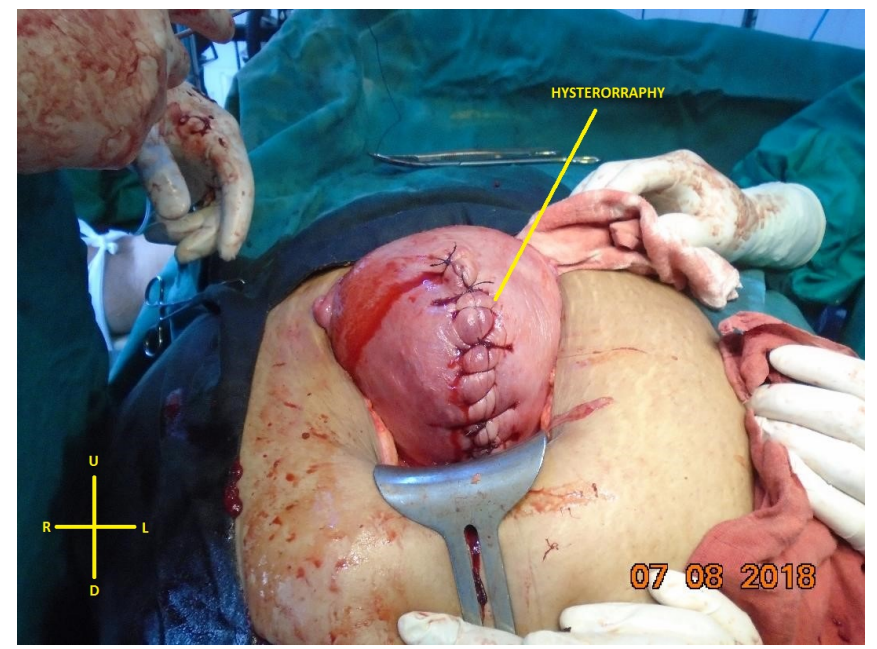

Figure 3. Uterus after hysterorhaphy. Title: $\mathbf{U}=\mathrm{Up}, \mathrm{D}=$ Down, $\mathbf{R}=$ Right, $\mathrm{L}=$ Left. 


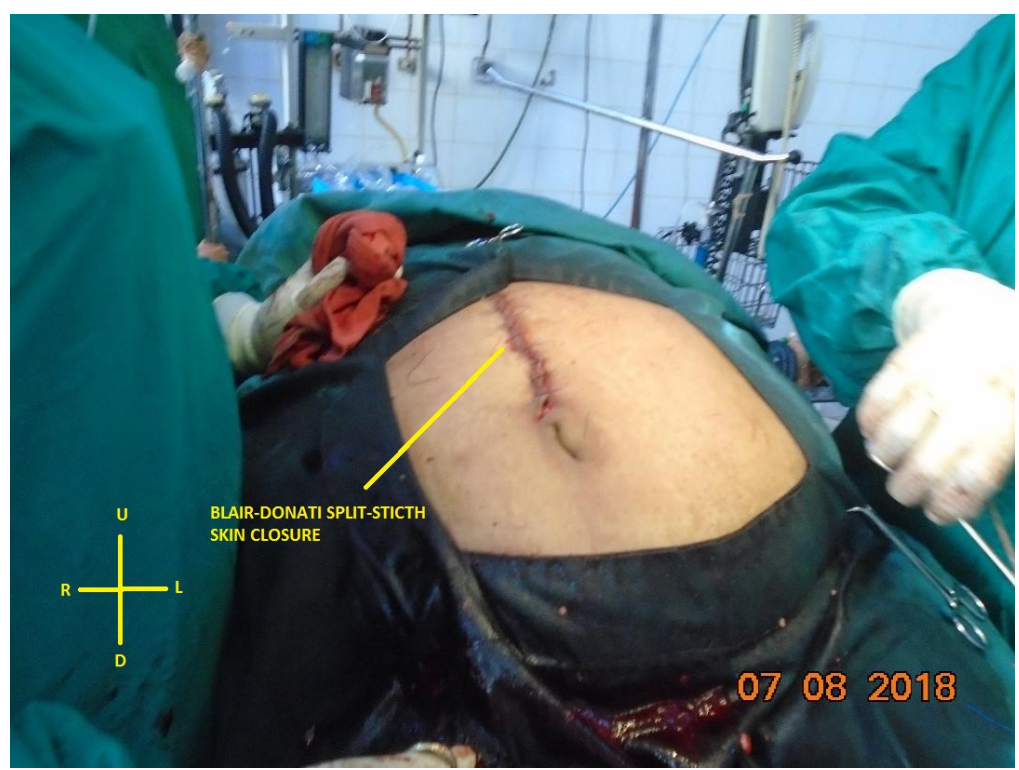

Figure 4. Abdominal wall after closure. Title: $\mathbf{U}=\mathrm{Up}, \mathbf{D}=$ Down, $\mathbf{R}=$ Right, $\mathbf{L}=$ Left.

complications associated with this morbid association. The frequency of obesity in pregnancy varies from country to country, but globally ranges from $6 \%$ to $20 \%$ [3] [4]. In West Africa, we find a rate of $11.3 \%$, with an average age of 30 years, and a high socioeconomic level [5]. This observation leads us to raise awareness among pregnant women who are basically overweight about the considerable weight gain during pregnancy, and to revisit their diet during this period.

At present, there is no consensus on the surgical technique for Caesarean section, ranging from super-obesity to mega-obesity, and from the surgical principle of skin to fetal extraction. In our patient, we proceeded with a median supra umbilical incision of $15 \mathrm{~cm}$ in length (Figure 1), the adipose panniculus was retracted with right angle valves and the dean's valve; easily allowing for a median fasciotomy and coeliotomy, hysterotomy was corporal. According to the French and Anglo-Saxon literature [1] [6] several incision variants can be used: the supra umbilical and sub umbilical variants can be median or transverse; the technique of aponeurotic and muscular dissection is classic; the hysterotomy for the most part is corporal anterior [1] [7]. Nevertheless, in these surgical procedures, a difficulty lies in the management of the fatty panicle; according to Mashak Banafsheh [8], in the supra-umbilical approach, the valves alone would be sufficient to retract the fatty panicle, on the other hand, in the sub-umbilical approach, it would be of interest to pull the fatty panicle with leukoplast towards the thorax to allow greater ease of movement during the operation [8].

Generally, the postoperative course depends on the approach used to perform the caesarean section; in the case of our patient we performed a median supra umbilical incision and the postoperative course were unremarkable; the patient was discharged on the 7th day. This evolution corresponds to the data in the literature; in American series comparing the postoperative window between two 
groups of incisions (vertical supra umbilical and transverse sub umbilical) we note that the vertical supra umbilical incision exposes to fewer post-operative complications than the transverse one [6]. Moreover, this approach reduces the intervention time and neonatalmorbidity [9] [10].

\section{Conclusion}

Obesity is a systemic disease with a significant frequency in our country. In pregnant women, it alters the prognosis of childbirth in favour of caesarean section. In view of this clinical case, the approach we recommend is the vertical supra umbilical incision because it is subject to fewer complications and reduces the operating time and hospital stay.

\section{Authors' Contributions}

Fouelifack received, took charge of the patient and initiated the manuscript, Tatsipie and Kamga participated in the writing of the manuscript as well as its translation from French to English, Mosman translated the manuscript from French to English, Fouedjio participated in the writing of the manuscript.

\section{Acknowledgements}

We would like to thank the patient who kindly gave her consent for this study.

\section{Ethical Considerations}

Prior to the procedure we expressed our desire to publish the case and obtained verbal permission from the patient to take the images and write the manuscript for publication, provided that anonymity was maintained. The information received was treated in the strictest confidence.

\section{Conflicts of Interest}

The authors declare no competing interest.

\section{References}

[1] Stewart, Z., Dolley, P., Beucher, G., Villot, A. and Dreyfus, M. (2017) Supraumbilical Transverse Incision for Cesarean Section in Severely Obese Patients: The Experience of a French Hospital from 2009 to 2014. Open Journal of Obstetrics and Gynecology, 7, 1024-1034. https://doi.org/10.4236/ojog.2017.710103

[2] Taylor, C.R., Dominguez, J.E. and Habib, A.S. (2019) Obesity and Obstetric Anesthesia: Current Insights. Local and Regional Anesthesia, 12, 111-124. https://doi.org/10.2147/LRA.S186530

[3] Pathi, A., Esen, U. and Hildreth, A. (2006) A Comparison of Complications of Pregnancy and Delivery in Morbidly Obese and Non-Obese Women. Journal of Obstetrics and Gynaecology, 26, 527-530. https://doi.org/10.1080/01443610600810914

[4] Callaway, L., Prins, J.B., Change, A. and Tyre, H. (2006) The Prevalence and Impact of Overweight and Obesity in an Australian Obstetric Population. Medical Journal 
of Australia, 184, 56-59. https://doi.org/10.5694/j.1326-5377.2006.tb00115.x

[5] N'Guessan, K., Knabben, L., Abauleth, R., Angoi, V., Nigue, L. and Boni, S. (2008) Obesity and Pregnancy: An African Experience Involving 506 Patients. Letter of the Gynecologist, 328-329, 6-9.

[6] Osmundson, S.S., Grasch, J.L. and Thompson, J.L. (2018) Skin Incision in Superobese Women Undergoing Cesarean Delivery. American Journal of Obstetrics and Gynecology, 218, 325. https://doi.org/10.1016/j.ajog.2017.11.071

[7] Marrs, C.C., Moussa, H.N., Sibai, B.M. and Blackwell, S.C. (2014) The Relationship between Primary Cesarean Delivery Skin Incision Type and Wound Complications in Women with Morbid Obesity. American Journal of Obstetrics \& Gynecology, 210, 319. https://doi.org/10.1016/j.ajog.2014.01.018

[8] Mashak, B., Sadati, L., Nosrati, S., Frouzesh, R. and Torkmandy, H. (2017) Evaluation of Two Techniques for Transverse Exposure in Obese Patients Undergoing Cesarean Section: A Comparative Study. Journal of Clinical and Basic Research, 1, 29-35.

[9] Wall, P.D., Deucy, E.E., Glantz, J.C. and Pressman, E.K. (2003) Vertical Skin Incisions and Wound Complications in the Obese Parturient. Obstetrics \& Gynecology, 102, 952-956. https://doi.org/10.1016/S0029-7844(03)00861-5

[10] Girsen, A.I., Osmundson, S.S., Naqvi, M., Garabedian, M.J. and Lyell, D.J. (2014) Body Mass Index and Operative Times at Cesarean Delivery. Obstetrics \& Gynecology, 124, 684-689. https://doi.org/10.1097/AOG.0000000000000462 